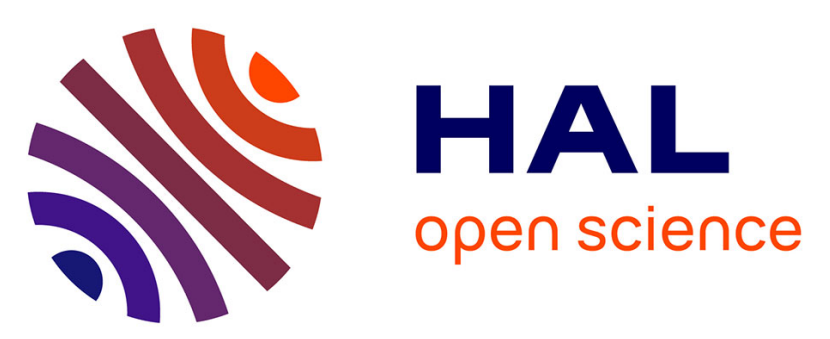

\title{
Retrieval of Forest Stand Age From SAR Image Texture for Varying Distance and Orientation Values of the Gray Level Co-Occurrence Matrix
}

Isabelle Champion, Christian Germain, Jean-Pierre da Costa, Arnaud Alborini, Pascale Dubois-Fernandez

\section{To cite this version:}

Isabelle Champion, Christian Germain, Jean-Pierre da Costa, Arnaud Alborini, Pascale DuboisFernandez. Retrieval of Forest Stand Age From SAR Image Texture for Varying Distance and Orientation Values of the Gray Level Co-Occurrence Matrix. IEEE Geoscience and Remote Sensing Letters, 2014, 11 (1), pp.5-9. 10.1109/LGRS.2013.2244060 . hal-00903994

\section{HAL Id: hal-00903994 \\ https://hal.science/hal-00903994}

Submitted on 13 Nov 2013

HAL is a multi-disciplinary open access archive for the deposit and dissemination of scientific research documents, whether they are published or not. The documents may come from teaching and research institutions in France or abroad, or from public or private research centers.
L'archive ouverte pluridisciplinaire HAL, est destinée au dépôt et à la diffusion de documents scientifiques de niveau recherche, publiés ou non, émanant des établissements d'enseignement et de recherche français ou étrangers, des laboratoires publics ou privés. 


\title{
Retrieval of Forest Stand Age From SAR Image Texture for Varying Distance and Orientation Values of the Gray Level Co-Occurrence Matrix
}

\author{
Isabelle Champion, Christian Germain, Jean Pierre Da Costa, Arnaud Alborini, \\ and Pascale Dubois-Fernandez
}

\begin{abstract}
Data on forest variables (e.g., biomass, trunk height, density) are necessary for environmental and forest management applications. It has been shown that texture can be used instead of the usual $\sigma_{o}$ /age relationships at P-band to retrieve plantation forest parameters, but the analysis of $\sigma_{o}$ spatial characteristics has not been fully explored. The aim of this letter is to investigate the relationships between stand age (which is correlated to forest variables) and texture descriptors calculated from statistics generated by the gray-level co-occurrence matrix for varying distance $d$, and orientation $\alpha$, values used to calculate the matrix. Synthetic aperture radar images are P-band airborne data acquired by the ONERA RAMSES instrument over a controlled homogeneous test site located in the Landes region, France. It is found that texture descriptors contrast, inverse difference moment, homogeneity, and correlation are strongly influenced by the parameters $(d, \alpha)$ related to forest stand structure (forest rows, stand density) and image resolution. In contrast, energy and entropy are observed to be highly correlated to stand age and displayed a stable performance whatever the distance and orientation parameters $(d, \alpha)$, thus rendering them a good contender as an alternative to the usual $\sigma_{o}$ based relationships applied to this type of forest.
\end{abstract}

Index Terms-Biomass, forestry, image texture analysis, radar applications, remote sensing, synthetic aperture radar (SAR).

\section{INTRODUCTION}

$\mathbf{I}$ NTEREST in the world's forests has risen to unprecedented heights, especially with increasing awareness of their role in the global carbon cycle and the necessity to regularly quantify carbon stocks as inferred from tree biomass. Synthetic aperture radar (SAR) systems have demonstrated their potential for discriminating biomass volumes in young to mature stands, especially at low frequencies, e.g., the L- or P-bands.

Manuscript received October 1, 2012; revised January 14, 2013; accepted January 23, 2013. Date of publication March 13, 2013; date of current version November 8, 2013. This work was conducted under a European Space Agency contract.

I. Champion is with the National Agronomical Research Institute, INRA, UR1263 EPHYSE, Villenave d'Ornon 33140, France (e-mail: champion@bordeaux.inra.fr).

C. Germain, J. P. da Costa, and A. Alborini are with the Material to Systems Integration (IMS) Laboratory, CNRS: UMR5218Sciences and Technologies University. Bordeaux I, IPB Bordeaux, France (e-mail: christian.germain@ims-bordeaux.fr; jean-pierre.dacosta@imsbordeaux.fr; alborini@enseirb-matmeca.fr).

P. Dubois-Fernandez is with the French National Aerospace Research Center, ONERA, Salon 13661, France (e-mail: pascale.duboisfernandez@onera.fr).

Digital Object Identifier 10.1109/LGRS.2013.2244060
Significant relationships have been established between radar mean intensity and biophysical variables [1], [2], including biomass [3]. However, for mature stands (about 80 t.ha $^{-1}$ and more) increasing the amount of biomass has been shown to reduce the sensitivity of backscattering coefficient $\sigma_{o}$ /biomass relationships [4].

If available, LIDAR data that supply height estimations can be combined with SAR imagery to improve biomass estimations [5]. Canopy height can also be retrieved using an SAR technique known as polarimetric interferometry (PolInSAR), which has the advantage of providing both height and biomass measurements independently using the same sensor [6].

When such systems are not available, studies have shown that the spatial distribution of gray levels within an SAR image can also help in characterizing vegetation cover. During recent decades, texture features have been widely used in the field of image processing for forestry applications to improve land use classifications for various types of forests: temperate [7], boreal [8], [9], or naturally regenerating tropical forest [10], [11]. However, few studies have explored SAR image texture to directly infer age or related forest parameters (trunk diameter or biomass), as is generally done with $\sigma_{o}$ /biomass relationships.

In the case of a temperate, even-aged, cultivated pine forest, it has been shown that significant relationships can be established between texture features and forest stand age [12] or aboveground biomass [13]. This suggests that texture could be used rather than the usual $\sigma_{o}$ /age relationships, even for such mature stands where the highest biomass values reach around 140 t.ha $^{-1}$.

These studies explored texture features derived from the statistics of pixel pairs captured in the gray-level co-occurrence matrix (GLCM) [14] computed for space shifts $(d, \alpha)$, where $d$ is the distance between the pixels and $\alpha$ is the orientation of the translation vector defining the pixel pair.

The objective of this letter is therefore to evaluate the relationships between texture descriptors and forest stand age for different values of $(d, \alpha)$. After describing the dataset (Section II), the impacts of $(d, a)$ values are analyzed (Section III) in terms of the spatial structures likely to produce image texture: forest row orientation, forest density, and image resolution. 


\section{MATERIALS AND MeTHOdS}

\section{A. Radar Images}

The SAR data analyzed are high resolution, complex polarimetric images acquired on January 21, 2004 using the airborne ONERA system [15] operating at $\mathrm{P}$ band $(0.427 \mathrm{GHz})$. The weather was damp during the period preceding the flight, with rain on the previous days and a wind from west-north-west. On the day of measurement, it was cloudy with some bright intervals in the afternoon.

Single-look SAR data incidence angle varies within an image from $10^{\circ}$ in the near range to $60^{\circ}$ in the far range. Only stands lying within the incidence angle range of $20^{\circ}$ to $40^{\circ}$ were selected for the study. However, as illumination geometry could be responsible for some texture variations, an analysis of variance was performed [12] and showed that the image incidence angle does not significantly influence texture features.

Under the SAR system, each data set refers to single-look complex images with cross (HV) and parallel polarizations $(\mathrm{HH}, \mathrm{VV})$ where the two letters indicate the polarization of both the transmit antenna and receiving antenna, with $\mathrm{H}$ being horizontal and V vertical. Pixels are $3.21 \times 2.46 \mathrm{~m}^{2}$, where $2.46 \mathrm{~m}$ is the radial projected resolution $(\mathrm{at}-3 \mathrm{~dB})$ and $3.21 \mathrm{~m}$ the projected azimuth resolution [15]. In order to correct the complex radar cross section values (RCS values $\mathrm{m}^{2}$ ) for the incident angle, RCS imaginary and real parts (Im and Re) were transformed into $\sigma_{o}$ values as a function of the incidence angle $\theta$, as shown in

$$
\sigma_{o}=10 * \log 10\left(\left(\mathrm{Im}^{2}+\mathrm{Re}^{2}\right) * \sin (\theta) / A\right)
$$

where $\theta$ is a function of the sensor height and the pixel distance in the range direction and $A$ is the resolution surface, i.e., the slant range resolution times the azimuth resolution.

Finally, the $\sigma_{o}$ images were transformed into intensity values of between 0 and 1 to enable comparisons between images and to calculate the gray-level co-occurrence matrix.

\section{B. Ground Dataset}

The INRA Nezer experimental test site is located in the northern part of the Landes forest in France. It contains welldefined planted stands of maritime pines (Pinus pinaster Ait.), which all receive identical sylvicultural treatments. Ranging from seedlings to mature trees, the pine trees are sown or planted in rows with 4-m spacing over a nearly flat surface. Each stand is rectangular in shape, delimited by fire protection clearings or access tracks, and covers about 25 ha. The stand ages are all known [12].

Within stands representing all ages, homogeneous patchessquares of equal size-were carefully selected using aerial photos from the French Geographical Institute [Institut Géographique National (IGN)] in order to eliminate any disturbances resulting from localized damages, such as windstorms or fire. The sampling had to cover a range of stand ages from 2 to 51 years old age to be representative of the forest. The patches needed to be large enough to capture spatial variations linked to crown growth and stand structure modifications over the years. In accordance with all these requirements, a sample of 16 homogeneous square patches with an area of $60 \times 60$

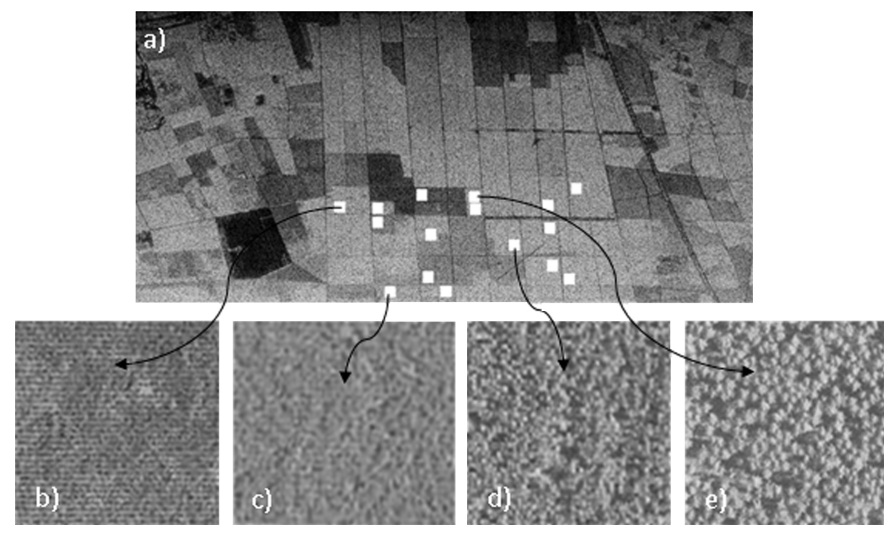

Fig. 1. Subset of an SAR HV image of the (a) Nezer forest and (b)-(e) aerial photographs (@IGN) of four homogeneous stands with ages varying from (b) 6 , (c) 11 , (d) 22 to (e) 51 years. Tree rows are in an east-west direction along the line direction of the SAR image. The rows are especially pronounced in young stands (7- and 11-years-old) and tend to vanish with successive thinnings in mature stands.

pixels is therefore selected (Fig. 1). The upper limit of the patch size is defined by the largest homogeneous zone within the oldest stands, most of these having been reduced in size by the Martin windstorm in December 1999.

\section{Calculation of Texture Descriptors}

The probability distribution of backscattering coefficients is determined by superposing scene radiometric and textural information along with speckle noise, the latter generally being considered a random process statistically independent of the textural variations associated with spatial variations in the scattering properties of visually uniform distributed targets [16]. As a result, image texture consists of two-layered information, involving tonal primitives of the image and their spatial organization [16].

In order to capture distribution modifications of the backscattering coefficient with stand age, we used texture descriptors for this study that were derived from GLCM. A GLCM represents the statistical dependence between two pixels $\left(p_{i j}, p_{i+1, j+m}\right)$, where $i$ and $j$ are the line and column numbers in the image, 1 and $\mathrm{m}$ are the distance between lines and columns from one pixel to the other. $\left(\mathrm{p}_{\mathrm{ij}}, \mathrm{p}_{\mathrm{i}+1, \mathrm{j}+\mathrm{m}}\right)$ is defined by the same relative position: $(1, \mathrm{~m})$ in Cartesian coordinates or $(d, \alpha)$ in polar coordinates.

In short, a GLCM is a bidimensional histogram of the pixel pair gray levels from which various descriptors can be computed [14]. Six of these are explored for our purposes: energy (or uniformity), contrast, inverse difference moment (IDM), homogeneity, correlation, and entropy. These descriptors would capture the spatial dependence of pixel intensities, thus providing information about forest structures.

In order to compute the GLCM, the gray-tone image is quantified into $2^{n}$ levels with $n$ usually varying from 3 to 6. In this letter, intensity images were quantified into $2^{5}=32$ levels, which was a tradeoff between information and calculation time.

In general, only small distances and a few angles are considered, typically $d \in\{1,2\}$ and $\alpha \in\left\{0^{\circ}, 45^{\circ}\right\}$. GLCMs 


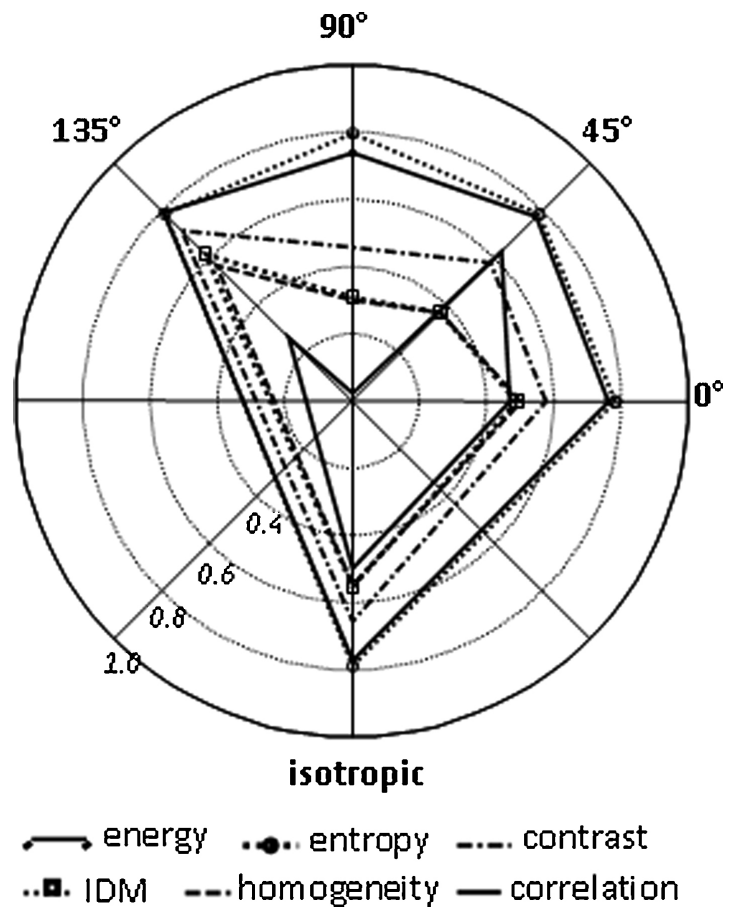

Fig. 2. $R^{2}$ values for HV polarization. $R^{2}$ values are plotted as a function of the $\alpha$ directions in polar coordinates for texture descriptors derived from the GLCM matrix calculated using $d=1 . \alpha$ characterizes the orientation of the pixel pairs used to calculate the GLCM. The $\alpha$ directions are represented in the superior hemisphere. The mean value between all directions is plotted on the bottom part (isotropic).

can also be computed in an isotropic manner by averaging $\alpha$ over various angles: $0^{\circ}, 45^{\circ}, 90^{\circ}$, and $135^{\circ}$. For this letter (see Section III-A), GLCM were first calculated for $\alpha\left\{0^{\circ}, 45^{\circ}, 90^{\circ}\right.$, $135^{\circ}$, isotropic $\}$.

In a second phase (see Section III-B), GLCM were calculated using a large range of $d$ values (1 to 15$)$ to cover situations involving neighboring pixels $(d=1)$ and those where pixels were separated by a distance corresponding to several tree rows or crowns (for mature stands) when $d$ increased to 15 . For each $d$ value, various $\alpha$ directions were tested.

In each test series (Sections III-A and III-B), the matrices were rendered symmetrical by counting the gray level cooccurrences for both $\alpha$ and $a+180^{\circ}$. Texture descriptors were derived from the GLCMs for each $(d, \alpha)$ value by using SAR images at cross and parallel polarizations. The quality of the linear regression between stand age and the texture descriptor was characterized by the determination coefficient $\left(R^{2}\right)$ and the $T$ student statistic. The results are first discussed for all polarizations, but special attention was paid to the results obtained at $\mathrm{HV}$ polarization, given that $\mathrm{HV}$ is generally used in studies of the relationships between $\sigma_{o}$ and forest parameters.

\section{RESULTS AND DisCUSSION}

\section{A. Variation of the Angle $\alpha$}

It can be seen from Fig. 2 that energy and entropy behaved similarly with regard to direction $\alpha$, as well as IDM and homogeneity. Contrast and correlation behaved differently
TABLE I

$R^{2}$ Determination Coefficients of Linear Regressions: Age Versus TEXTURE DESCRIPTORS DERIVED FROM THE GLCM MATRIX

\begin{tabular}{|c|c|c|c|c|c|c|}
\hline$\alpha$ direction & energy & contrast & IDM & Homog. & Correl. & entropy \\
\hline$\alpha=0^{\circ} / 180^{\circ}$ & $0.76 \nLeftarrow$ & $0.58 * 4$ & $0.49 * *$ & $0.50^{* *}$ & $0.47^{+*}$ & $0.78^{+4+4}$ \\
\hline$\alpha=135^{\circ} / 45^{\circ}$ & $0.79 * 4$ & $0.72^{4+4}$ & $0.61^{+*}$ & $0.57^{* *}$ & 0.26 & $0.79+4 *$ \\
\hline$\alpha=90^{\circ} /-90^{\circ}$ & $0.74 \nleftarrow$ & $0.46^{+4}$ & 0.31 & 0.30 & 0.02 & $0.79+4 \phi$ \\
\hline$\alpha=45^{\circ} /-135^{\circ}$ & $0.78 \%$ & $0.59+4$ & 0.37 & 0.37 & $0.63^{+4}$ & $0.79+4+$ \\
\hline Isotropic & $0.77 * 4$ & $0.69 * 4 *$ & $0.60^{* 4}$ & $0.58 * 4$ & 038 & $0.79+44$ \\
\hline$\alpha=0^{\circ} / 180^{\circ}$ & $0.81+4$ & $0.59+4$ & $0.50^{+*}$ & $0.52^{+4}$ & $0.44^{+*}$ & $0.80^{+4+4}$ \\
\hline$\alpha=135^{\circ} / 45^{\circ}$ & $0.80 \div 4$ & $0.62^{+4}$ & $0.54^{+4}$ & $0.52^{4+}$ & 039 & $0.81^{4+4}$ \\
\hline$\alpha=90^{\circ} /-90^{\circ}$ & $0.80 \% 4$ & 0.33 & 029 & 0.27 & 0.11 & $0.81^{+4+}$ \\
\hline$\alpha=45^{\circ} /-135^{\circ}$ & $0.79 \nLeftarrow 4$ & $0.65^{+4}$ & $0.66^{++4}$ & $0.67+4+$ & $0.47^{+*}$ & $0.81^{+4+}$ \\
\hline Isotropic & $0.81 * 4$ & $0.65^{+*}$ & $0.56^{+*}$ & $0.55^{+4}$ & $0.52^{*+}$ & $0.81^{+4 *}$ \\
\hline$\alpha=0^{\circ} / 180^{\circ}$ & $0.68+4$ & 0.17 & $0.57^{+4}$ & $0.57^{+*}$ & $0.54+4$ & $0.66^{+4+}$ \\
\hline$\alpha=135^{\circ} / 45^{\circ}$ & $0.65 \div 4$ & 0.32 & 0.43 & 0.42 & 0.36 & $0.68^{4+4}$ \\
\hline$\alpha=90^{\circ} /-90^{\circ}$ & $0.67^{+4}$ & 0.25 & 021 & 0.19 & 022 & $0.67^{+4+}$ \\
\hline$\alpha=45^{\circ} /-135^{\circ}$ & $0.68 \div 4$ & $0.47^{* *}$ & $0.62^{+4}$ & $0.62^{+*}$ & 0.07 & $0.68 * 4+$ \\
\hline Isotropic & $0.67+4$ & 0.31 & $0.50^{+4}$ & $0.50^{+4}$ & $0.53^{+4}$ & $0.67^{+4+}$ \\
\hline
\end{tabular}

GLCM is performed for $25=32$ levels of intensity values and for neighboring pixel pairs (distance $d=1$ ). Regressions are considered highly significant for $\mathrm{p}$-values $<0.0001(* * *)$ or $\mathrm{p}$-values $<0.005(* *)$, the degree of freedom is 14 .

from the other descriptors. In particular, correlation varied considerably with $\alpha$ relative to tree row width and orientation.

Table I shows the strength of the relationships between texture descriptors and stand age for various $\alpha$ for $d=1$ at $\mathrm{HH}$, $\mathrm{VV}$ and HV polarizations. $R^{2}$ values were generally lower for the VV polarization. $\mathrm{HH}$ and $\mathrm{HV}$ displayed similar variations except for contrast, where HV was slightly better than $\mathrm{HH}$.

The linear regressions between energy and stand age, and between entropy and stand age, were highly significant, with p-values $<0.0001$, whatever the polarization and direction $\alpha$ considered in the GLCM matrix calculation. On the other hand, contrast, homogeneity, and IDM $R^{2}$ values varied with $\alpha$, especially regarding the correlation for which regression with stand age produced $R^{2}$ values up to 0.5 for $\alpha=0^{\circ}$, and which decreased drastically when $\alpha=90^{\circ}$.

Contrast, homogeneity, IDM, and correlation were therefore strongly influenced by the direction of the pixel pairs defined by $\alpha$, which were accounted for in the GLCM calculation. The tracking direction of the airborne SAR was oriented perpendicular to the tree rows, which were themselves aligned to the image lines (range direction). Parameters $\left(d=1, \alpha=0^{\circ}\right)$ concerned pixel pairs oriented along the tree rows, while parameters $\left(d=1, \alpha=90^{\circ}\right)$ involved pixel pairs oriented across the rows. It appears that some texture indicators extracted from the GLCM, i.e., correlation, IDM, contrast and, to a lesser extent, homogeneity were markedly impacted by tree rows.

\section{B. Variation of the Distance $d$}

When $d$ increased from 1 to 15, it can be seen from Fig. 3 that energy and entropy show displayed quite significant and stable regressions ( $R^{2}$ between 0.7 and 0.8 ) whatever the distance $d$ in the GLCM calculation.

However, $R^{2}$ was strongly impacted by the $d$ values for contrast, IDM, homogeneity, and correlation. It displayed regular variations of over 3 or 4 pixels along $\left(\alpha=0^{\circ}\right)$ or across the rows $\left(\alpha=90^{\circ}\right)$, especially for IDM and homogeneity. 

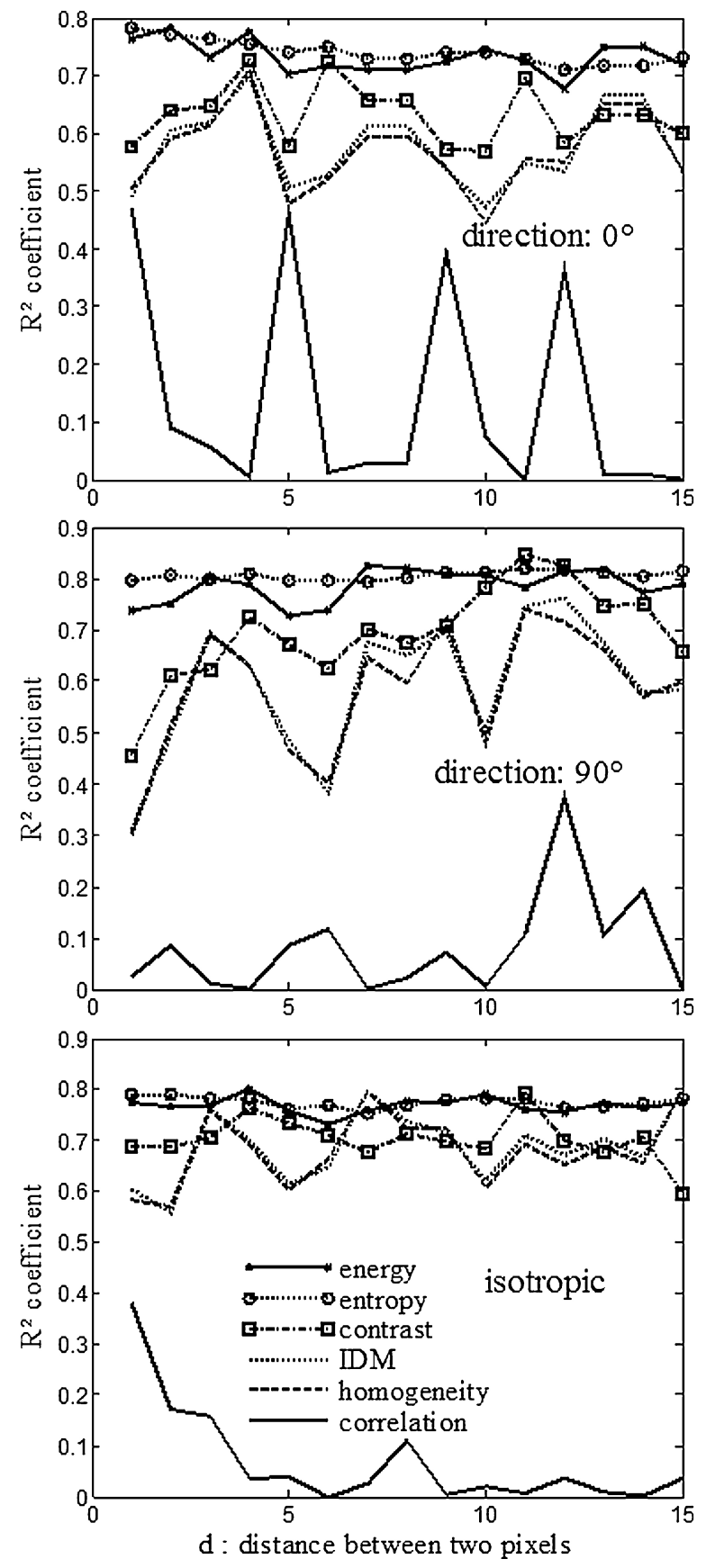

Fig. 3. $\quad R^{2}$ coefficients of stand age versus texture descriptors as a function of distance $d$ for HV polarization. Along the rows (direction $\alpha=0^{\circ}$ ): pixel pairs are located on the same line. Across the rows (direction $\alpha=90^{\circ}$ ): pixel pairs are located on the same image column. Isotropic is the average of all $\alpha$ directions.

The variations in regression quality observed in Fig. 3 were probably related to a combination of stand structure (tree size, row size, stand density) and image resolution. Image resolution was $3.21 \mathrm{~m}$ in the east-west line $\left(\alpha=0^{\circ}\right)$ along the rows. Radial image resolution was $2.46 \mathrm{~m}$ along the image columns $\left(\alpha=90^{\circ}\right)$, i.e., across the tree rows in the north-south direction.

Consequently, across the rows, regular variations of $R^{2}$ were observed for IDM, homogeneity and contrast over a distance

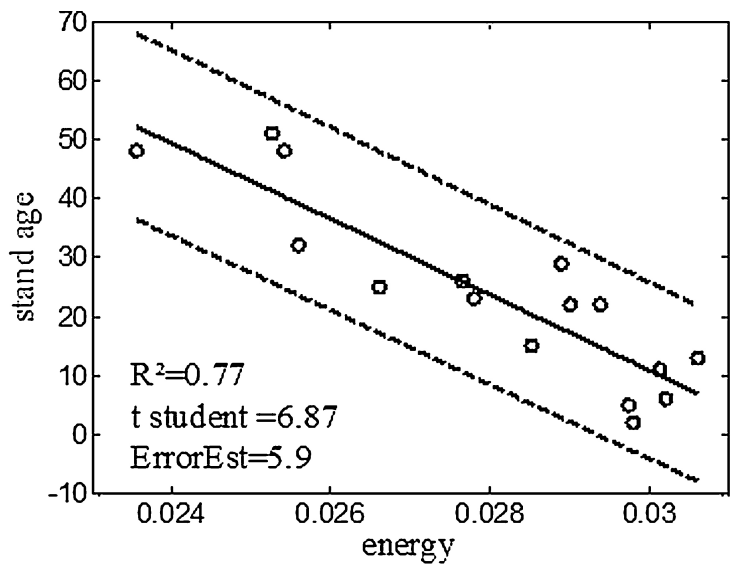

(a)

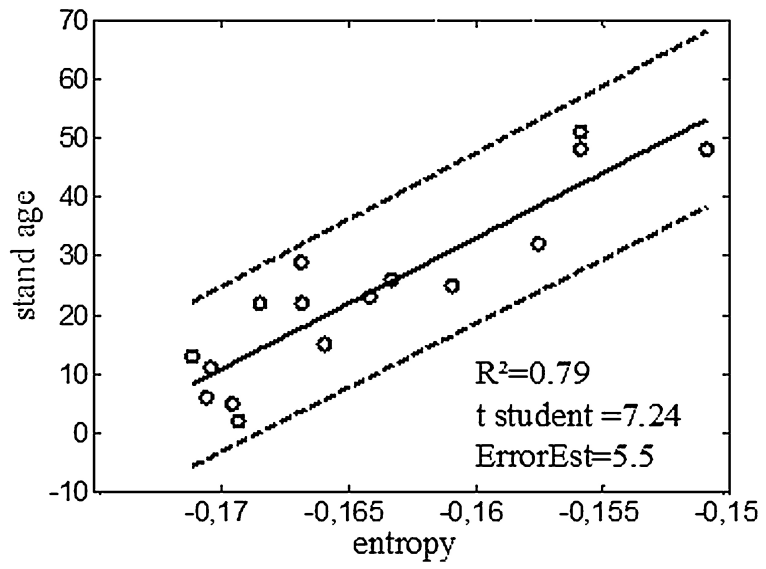

(b)

Fig. 4. Observed data (o) and least-square linear fit (solid lines) of stand age versus: (a) energy, (b) entropy derived from GLCM, calculated with a distance ( $d=1$, isotropic) for HV polarization. The determination coefficient $R^{2}$, the $T$ student factor, and the mean error estimation (ErrorEst) for prediction of the age are displayed. The estimate of the standard deviation of the error in predicting a future observation (age when using the texture descriptor) is indicated by dashed lines.

of about 8 to $10 \mathrm{~m}$, which was a multiple of the row width for younger stands with well-marked rows.

Along the rows, a space of 14 pixels was equivalent to approximately five or six tree crowns for mature stands with the highest backscattering coefficients. Stands older than 25 years had a density ranging from about 300 tree.ha $^{-1}$ down to less than 200 tree.ha $^{-1}$, i.e., about one tree for every two or three pixels in the azimuth direction provided that the thinning pattern was regular.

Finally, the best regressions was observed for energy or entropy that could then be used as regressands (Fig. 4) to predict stand age. For this example ( $d=1$, isotropic, polarization HV), stand age could be retrieved with an uncertainty of less than six years when using these texture descriptors.

\section{CONCLUSION}

Texture descriptors, namely, GLCM were computed on an SAR P band image of the Landes pine forest, at cross and parallel polarizations. Various pixel pair configurations were considered for calculation of the GLCM, i.e., the relative 
orientation $(\alpha)$ and distance $(d)$ separating the two pixels. The results showed that energy and entropy were highly correlated with stand age. For both indicators, texture/stand age regressions were not markedly impacted by the method used to calculate the GLCM and regressions did not reveal any marked optimum or minimum for distance $d$ or direction $\alpha$ that would enhance or reduce regression quality. Finally, no matter how the co-occurrence matrices were calculated, stand age varied linearly as a function of energy or entropy, with confidence levels superior to $95 \%$, and could be retrieved with an error lower than six years. Energy, and, particularly entropy, was therefore shown to be good candidates for the remote sensing of forest age using SAR images.

However, contrast, IDM, homogeneity, and correlation were strongly influenced by $\alpha$ direction and increasing mesh size (pixels separated by 1 to 15 pixels). These results could be related to image resolution and forest stand structure and architecture (crown size, thinning patterns, row width, direction, etc.).

The sensitivity of contrast, IDM, homogeneity, and correlation could now be explored as a function of stand structure, with further analyses on separate stands and by applying other analytical methods (Fourier transform, wavelet transform, etc.) to extract stand density and structure from image textures.

\section{ACKNOWLEDGMENT}

The authors would like to thank the RAMSES Team and the INRA Ground Team for this dataset. Data acquisitions were made possible by the French Procurement Agency (CNES).

\section{REFERENCES}

[1] M. C. Dobson, Ulaby, T. Le Toan, A. Beaudoin, E. S. Kasischke, and N. Christensen, "Dependence of radar backscatter on coniferous forest biomass," IEEE Trans. Geosci. Remote Sens., vol. 30, no. 1, pp. 412-415, Mar. 1992.

[2] T. Le Toan, A. Beaudoin, J. Riom, and D. Guyon, "Relating forest parameters to SAR data," IEEE Trans. Geosci. Remote Sens., vol. 30, no. 2, pp. 403-411, Mar. 1992.
[3] T. Le Toan, S. Quegan, I. Woodward, M. Lomas, N. Delbart, and G. Picard, "Relating radar remote sensing of biomass to modelling of forest carbon budgets," Climatic Change, vol. 67, pp. 379-402, Dec. 2004.

[4] T. Le Toan, S. Quegan, M. W. J. Davidson, H. Balzter, P. Paillou, K. Papathannassiou, S. Plummer, F. Rocca, S. S. Saatchi, H. Shugart, and L. Ulander, "The BIOMASS mission: Mapping global forest biomass to better understand the terrestrial carbon cycle," Remote Sens. Environ., vol. 115 , no. 11 , pp. 2850-2860, Nov. 2011.

[5] G. Sun and K. J. Ranson, "Forest biomass retrieval from lidar and radar," in Proc. IEEE Geosci Remote Sens. Symp., vol. 5. Jul. 2009, pp. V300-V303.

[6] F. Garestier, P. Dubois-Fernandez, I. Champion, and T. Le Toan, "Pine forest investigation using high resolution P-band PolInSAR data," Remote Sens. Environ., vol. 115, pp. 2897-2905, Nov. 2011.

[7] G. Sun and K. J. Ranson, "Radar modelling of forest spatial patterns," Int. J. Remote Sens., vol. 19, no. 9, pp. 1769-1791, Jun. 1998.

[8] D. Wu and J. Linders, "A new texture approach to discrimination of forest clearcut, canopy, and burned area using airborne C-band SAR," IEEE Trans. Geosci. Remote Sens., vol. 37, no. 1, pp. 555-563, Jan. 1999.

[9] V. V. Miles, L. P. Bobylev, S. V. Maximov, O. M. Johannessen, and V. M. Pitulko, "An approach for assessing boreal forest conditions based on combined use of satellite SAR and multi-spectral data," Int. J. Remote Sens., vol. 24, no. 22, pp. 4447-4466, Nov. 2003.

[10] W. A. Salas, M. J. Ducey, E. Rignot, and D. Skole, "Assessment of Jers1 SAR for monitoring secondary vegetation in Amazonia: I spatial and temporal variability in backscatter across chrono-sequence of secondary vegetation stands in Rondonia," Int. J. Remote Sens., vol. 23, no. 7, pp. 1357-1379, Apr. 2002.

[11] T. M. Kuplich, P. J. Curran, and P. M. Atkinson, "Relating SAR image texture to the biomass of regenerating tropical forests," Int. J. Remote Sens., vol. 26, no. 21, pp. 4829-4854, Nov. 2005.

[12] I. Champion, P. Dubois-Fernandez, D. Guyon, and M. Cottrel, "Radar SAR images texture as a function of forest stand age," Int. J. Remote Sens., vol. 29, no. 6, pp. 1795-1800, Mar. 2008.

[13] I. Champion, P. Dubois-Fernandez, and X. Dupuis, "Retrieving forest biomass from the texture of SAR images," EARSeL eProc., vol. 10, no. 2, pp. 102-109, Sep. 2011.

[14] R. M. Haralick, "Statistical and structural approaches to texture," Proc. IEEE, vol. 67, no. 5, pp. 786-814, May 1979.

[15] P. Dubois-Fernandez, F. Garestier, I. Champion, X. Dupuis, and P. Paillou, "Ramses $\mathrm{P}$ band and L band campaign over the Nezer forest: Calibration and polarimetric analysis," presented at the 6th Eur. Conf. Synthetic Aperture Radar, EUSAR, Dresde, Germany, 2006.

[16] F. T. Ulaby, F. Kouyate, B. Brisco, and T. H. Lee Williams, "Textural information in SAR images," IEEE Trans. Geosci. Remote Sens., vol. 24, no. 2, pp. 235-245, Mar. 1986. 